\title{
Genetic Diversity Analysis of Upland Rice (Oryza Sativa L.) Genotypes in Benshangul Gumuz, Ethiopia
}

\author{
Atsedemariyam Tewachew", Wassu Mohammed, Alemayehu Assefa \\ Ethiopian Institute of Agricultural Research, Pawe Agricultural Research center, Ethiopia
}

*Corresponding Author: Atsedemariyam Tewachew, Ethiopian Institute of Agricultural Research, Pawe Agricultural Research center, Ethiopia

\begin{abstract}
In Ethiopia, rice variety development started very recently and mainly dependent on introduction of breeding materials in which characterization and understanding of the genetic diversity of genotypes is the critical step. Therefore, this research was conducted with the objective of assessing the genetic diversity and principal components of upland rice genotypes. A total of 23 rice genotypes with genetic background of Asian and African rice were evaluated in randomized complete block design with three replications in 2017 main cropping season at Pawe and Assosa research station. Principal component analysis showed percentage total variance of PC1 (42.96\%), PC2 (13.46\%), PC3 (12.62\%) and PC4 (11\%) with total contribution of $80.04 \%$ variation. The genetic distance of genotypes estimated using Euclidean distance ranged from 0.95 to 11.39 with 5.18, 1.7 and $32.81 \%$ of mean genetic distance, standard deviation and coefficient of variation, respectively. The Dendrogram constructed using Unweighted Pair-group Method with Arithmetic means separated genotypes into seven distinct clusters of which Cluster III and II consisted of large number of genotypes (34.78\%) and one genotype, respectively. The rice genotypes with high seed yield and high mean values for most of the traits were grouped in Cluster VI and IV. Based on the research results it is possible to conclude that the considerable number of genotypes had high yield potential and grain yield quality, there is a wide range of genetic distances and variations among genotypes for most of the traits that could be potentially exploited in future breeding programs.
\end{abstract}

Keywords: Clustering, Diversity, Genetic distance, Rice and Principal component analysis.

\section{INTRODUCTION}

Rice (Oryza sativa L.) is one of the major and staple foods for more than half of the world's Human population. Approximately $90 \%$ of the world's rice is grown and consumed in Asia, whereas $50 \%$ of the population depends on rice for food (Tenorio et al., 2013). It is one of the most strategic crops in Africa, and particularly in Ethiopia (Kijima et al., 2008). Ethiopia has immense potentials for growing rice crop. Rice is grown under widely varying conditions of altitude and climate. It grows from sea level to as high as 3000 meters and it needs a hot and humid climate (MoARD, 2010). Rice has been gathered, consumed and cultivated by many people worldwide for more than 10,000 years longer than any other crop (Onyango, 2014). Rice was introduced in Ethiopia in the 1970s. However, it has been cultivated in small pocket areas though the country has suitable ecologies for rice productions but unsuitable for production of other food crops (MoARD, 2010).

The production of rice constraints are many of which the development of rice varieties with higher yield potential and greater yield stability are needed to tackle the food insecurity in many countries of the world (Dogara and Jumare, 2014). Rice is the most rapidly growing source of food crop in Africa, and significant importance to food security and food self-sufficiency in an increasing number of low-income food deficit countries (FAO, 2012). Annual rice production in subSaharan Africa is comprising $15 \%$ of the region's cereal production.

Rice is among the most important cereal crops grown in different parts of Ethiopia as food crop(MoA , 2009).The first step in breeding is characterization and understanding of the genetic diversity of genotypes. Principal component analysis is one of the important tools of diversity analysis. This technique is very helpful for identification of plant characters that categorize the distinctiveness among promising genotypes (Chakravorty et al., 2013). The knowledge of diversity and genetic distances of genotypes also helps to identify parental lines for hybridization programs. Therefore, this 
research was conducted with the objective to estimate genetic diversity of upland rice genotypes based on yield, yield related and grain quality traits.

\section{MATERIALS AND METHODS}

The experiment was conducted at two locations, namely Pawe Agricultural Research Center and Assosa Agricultural Research Center experimental sites during the main cropping season of 2017. PARC is located $575 \mathrm{Km}$ from Addis Ababa and its geographic locationis between $11^{\circ} 15^{\prime}$ 'and $11^{\circ} 23$ North latitude and $36^{\circ} 30^{\prime}$ East longitudes. Assosa is located at $10^{\circ} 03^{\prime} \mathrm{N}$ latitude and $34^{\circ} 59^{\prime} \mathrm{E}$ longitudes at about 1580meters above sea level. The mean annual rainfall is about $1275 \mathrm{~mm}$. The mean annual minimum and maximum temperatures of the area is also about 14 and 39OC, respectively.

A total of 23 upland rice genotypes were obtained from Fogera National Rice Research and Training Center. The genotypes were introduced from Africa Rice Center. The experiment was conducted in randomized complete block design with three replications. A plot consisting six rows of $5 \mathrm{~m}$ long by $1.2 \mathrm{~m}$ width $\left(6 \mathrm{~m}^{2}\right)$ with spacing of $0.2 \mathrm{~m}$ between rows, $0.3 \mathrm{~m}$ between plots and $1.5 \mathrm{~m}$ between blocks was used. Seed rate of $60 \mathrm{~kg} / \mathrm{h}$ was used and the seed was drilled in a row. Data on grain yield and other important agronomic traits and quality traits were collected on plot and individual plant basis at each location. The grain quality parameter was measured from randomly taken grain samples from each plot.

\subsection{Data Analysis}

\subsubsection{Principal Component Analysis}

Principal component analysis (PCA) was computed to find out the characters, which accounted more to the total variation. The data was standardized to mean zero and variance of one before computing principal component analysis. The principal component based on correlation matrix was calculated using SAS software.

\subsubsection{Genetic Distance and Clustering}

Genetic distance of 23 upland rice genotypes were estimated using Euclidean distance (ED) calculated from quantitative traits after standardization (subtracting the mean value and dividing it by the standard deviation) as established by Sneath and Sokal (1973) as follows:

$\mathrm{EDjk}=\sqrt{\sum_{i=1}^{n}(X i j-X i k)^{2}}$, Where; EDjk = distance between genotypes $\mathrm{j}$ and $\mathrm{k}$; $\mathrm{xij}$ and $\mathrm{xik}=$ phenotype traits values of the $\mathrm{i}^{\text {th }}$ character for genotypes $\mathrm{j}$ and $\mathrm{k}$, respectively; and $\mathrm{n}=$ number of phenotype traits used to calculate the distance. The distance matrix from phenotype traits was used to construct Dendrogram based on the Unweighted Pair-group Method with Arithmetic Means (UPGMA). The results of cluster analysis were presented in the form of Dendrogram. In addition, mean ED was calculated for each genotype by averaging of a particular genotype to the other 23 genotypes. The calculated average distance (ED) was used to estimate which genotype(s) is closest or distant to others.

\section{RESULTS AND DISCUSSION}

\subsection{Principal Component Analysis}

The PCA analysis results includes the factor scores of each character among the 23 rice genotypes, eigenvalues, percentage total variance accounted for by four principal components (PCs). This principal component analysis resulted in four principal components (PC1 to PC4) with eigenvalues ranged from 1.54 to 6.01 . The four principal components accounted varied percentage of total variance that ranged from 11 to $42.96 \%$ and accounted for $80.04 \%$ of the total variation. Ojhaet al. (2017) reported that principal component contributed $68.87 \%$ variation; Tuhina-khatunet al. (2015) and Sohrabi et al.(2012) also reported the first four principal components accounted for about $72.1 \%$ and $76.7 \%$ of the total variation respectively. According to Brejda et al. (2000), data were considered in each components with Eigen value $>1$ which determined at least $10 \%$ of the variation. The higher Eigen values were considered as best representative of system attributes in principal components. 
The PC1 showed $42.96 \%$ variability among traits, while PC2, PC3, and PC4 exhibited $13.46 \%$, $12.62 \%$ and $11 \%$ variability respectively. The first principal component (PC1) was relatively with higher value that includes days to heading, days to flowering, days to maturity, unfilled grains per panicle, kernel length and length width ratio. These traits had more contribution to the total diversity and they were responsible for the differentiation of the clusters. In principal component (PC2), characters like plant height, panicle length, kernel width, days to heading, days to flowering, thousand grain weight, protein content and grain yield had more contribution to the total genetic diversity and clustering of genotypes. In principal component (PC3), thousand grain weights, kernel length, kernel thickens, length width ratio, days to heading, days to flowering and days to maturity had relatively more contribution to the total genetic diversity and clustering of rice genotypes. In principal component (PC4), characters such as plant height, panicle length, fertile tillers per plant, thousand grain weight and kernel width had relatively more contribution to the total variance.

Table1. Principal component values of the first four principal components for 23 rice genotypes evaluated across location (Pawe and Assosa) in 2017.

\begin{tabular}{|c|c|c|c|c|}
\hline \multirow{2}{*}{ Traits } & \multicolumn{4}{|c|}{ Eigenvectors } \\
\cline { 2 - 4 } & PC1 & PC2 & PC3 & PC4 \\
\hline Days to heading & 0.356 & 0.179 & 0.169 & 0.05 \\
\hline Days to flowering & 0.349 & 0.217 & 0.163 & 0.087 \\
\hline Days to maturity & 0.38 & 0.114 & 0.108 & -0.051 \\
\hline Plant height(cm) & 0.119 & 0.489 & -0.395 & 0.15 \\
\hline Panicle length(cm) & 0.177 & 0.307 & -0.386 & 0.157 \\
\hline Fertile tiller per plan & 0.154 & -0.137 & -0.346 & 0.523 \\
\hline Unfilled grains per panicle & 0.215 & -0.148 & -0.174 & -0.142 \\
\hline Thousand grain weight(g) & 0.053 & 0.254 & 0.508 & 0.419 \\
\hline Kernel length(mm) & 0.349 & -0.109 & 0.276 & 0.087 \\
\hline Kernel width(mm) & -0.298 & 0.455 & 0.08 & 0.135 \\
\hline Kernel thickens(mm) & -0.334 & 0.176 & 0.329 & 0.052 \\
\hline Length width ratio(mm) & 0.362 & -0.256 & 0.16 & 0.011 \\
\hline Protein content $(\%)$ & 0.119 & 0.338 & 0.049 & -0.514 \\
\hline Grain yield(kg/h) & 0.148 & 0.198 & -0.042 & -0.422 \\
\hline Eigenvalues & 6.01493 & 1.88449134 & 1.767122 & 1.539357 \\
\hline Difference & 4.13044 & 0.11736898 & 0.227766 & 0.564119 \\
\hline Total variance \% & 0.4296 & 0.1346 & 0.1262 & 0.11 \\
\hline Cumulative total variance \% & 0.4296 & 0.5642 & 0.6905 & 0.8004 \\
\hline
\end{tabular}

PC1, first principle component; PC2, second principle component; PC3, third principle component and PC4, fourth principle component.

Thousand grain weights had a maximum contribution, others, viz. days to flowering, days to heading, kernel length and days to maturity had relatively high contribution to genetic divergence of genotypes. The characters which had more contribution to total genetic divergence are under the control of additive gene action and will offer a good scope of improvement through selection breeding. This result concurrence with Ojha et al. (2017) for plant height and kernel length. The output of PCA revealed that different traits contributed differently to the variation. These differences indicated the present of variability and considerable opportunity for improvement of different qualitative and quantitative traits. Important characters coming together in different PCs have tendency to remain together, which may be kept into consideration during utilization of these characters in breeding programme to bring about rapid improvement for yield and other associated traits.

\subsection{Genetic Divergence Analysis}

\subsubsection{Genetic Distances among Rice Genotypes}

The relationship among genetic distances of 253 pair of genotypes estimated for each location and mean values over locations was tested with regression analysis and the results is presented in Figure 1. The relationship was linear among the three estimated Euclidean distances of genotypes. The correlation coefficient between Euclidean distances (ED) of genotypes estimated from mean values of over locations and Pawe was positive $(r=0.93)$ and significant. Similarly, Euclidean distances of genotypes estimated from mean values of over locations and from mean values at Assosa had significant and positive correlation $(\mathrm{r}=0.94)$. The coefficient of determination between ED estimated 
from Assosa and pooled mean and between Assosa and Pawe were $\mathrm{R}^{2}=0.6366$ and $\mathrm{R}^{2}=0.7979$, respectively. This indicated the genetic distances measured from mean values of 14 traits from Assosa explain 63.66 and $79.79 \%$ the ED measured from Pawe site and over two locations, respectively (Figure 1). Therefore, it is justified to evaluate the genetic distances among rice genotypes based on the Euclidean distances of genotypes estimated from mean values of over locations.

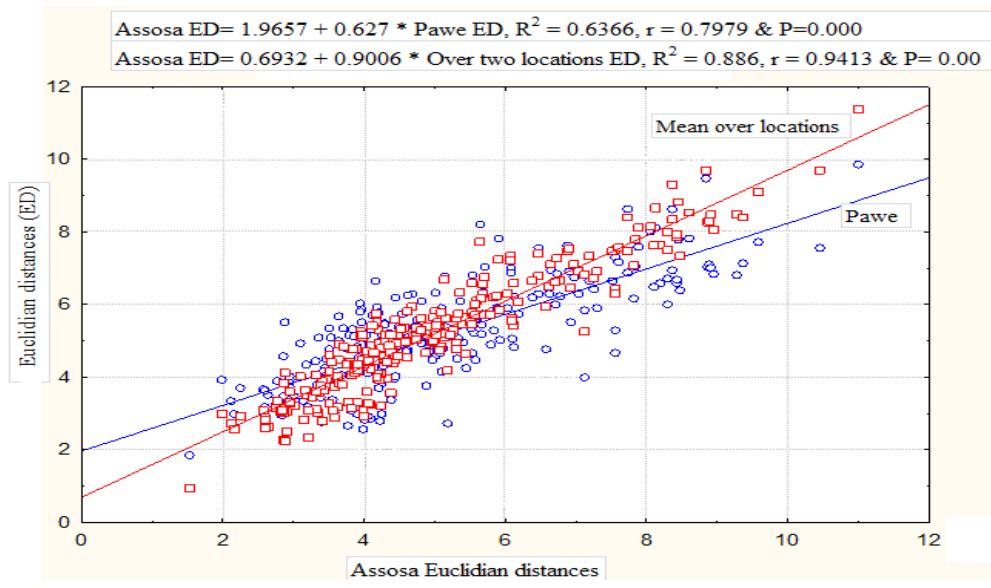

Figure1. Linear relationship among Euclidean distances of 253 pair rice genotypes estimated from mean values of genotypes at two locations (Assosa and Pawe) and mean values over two locations in 2017.

The genetic distance for all possible pairs of 23 rice genotypes ranged from 0.95 to 11.39 with the mean, standard deviation and coefficient of variation of 5.18, 1.7 and 32.81\%, respectively. The highest genetic distance (Euclidean distance) was computedbetween PARC.DAT.V2.2013 and A RT16-9-9-25-2-1-1-B-2-1 while the lowest genetic distance was estimated between ART16-21-4-7-22-B-2-2 and ART15-16-31-2-1-1-1-B-1-1. Among pair of genotypes, 17 (6.72\%), 47 (18.58\%) and 64 (25.30\%) pair of genotypes had Euclidean distances of 0.95-3, 3.01-4 and 4.01-5, respectively. A total of $125(49.41 \%)$ pair of genotypes had Euclidean distances ranged from 5.01 to 11.39 (Figure 2). Moreover, $112(44.27 \%)$ pair of genotypes had Euclidean distances $>5.18$ (overall mean ED of genotypes) of which $44(17.39 \%)$ had Euclidean distances $>6.88$ which was significantly higher (>overall mean ED + SD) than the overall mean ED of genotypes. This suggested considerable number of genotypes had genetic distances above the average genetic distance of the rice genotypes that could be considered for crossing programs to combine the desirable traits they possess. The genotypes with high genetic distances between them also have the potential to produce heterotic hybrids through crossing make among genotypes. Similar studies were reported by (Sohrabi et al., 2012).

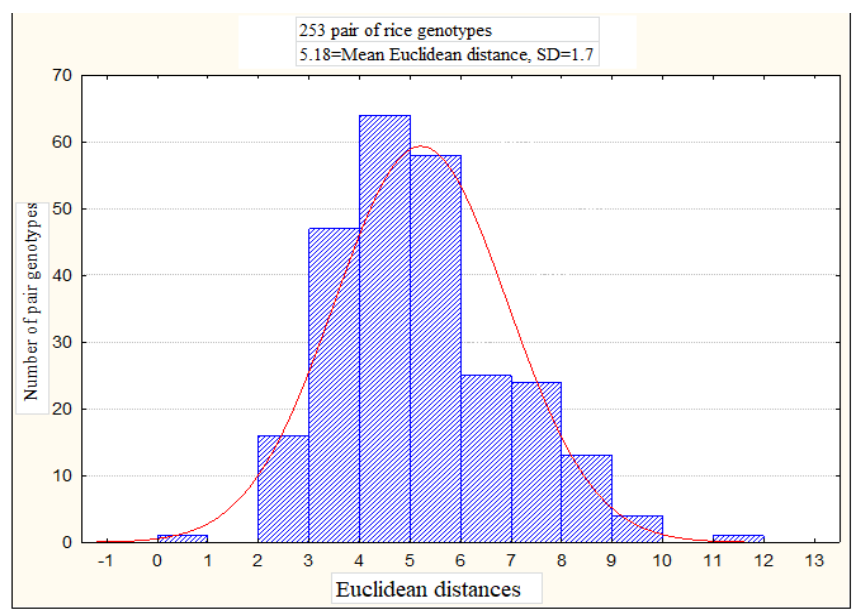

Figure2. Distribution of 253 pair rice genotypes across Euclidean distances of 0.95 to 11.39 estimated from mean values of 23 rice genotypes for 14 quantitative traits evaluated over two locations (Assosa and Pawe) in 2017.

The released variety, NERICA-4 included as a check in the experiment had also mean ED of 4.64 to other 22 genotypes which was lower than the overall mean ED of genotypes. The results suggested that the genotypes that had mean genetic distances over the average mean distance were more distant to others while the genotypes with mean genetic distances lower than the average mean distance of genotypes were more closest to other genotypes. 
Table2. Range and mean Euclidean distance of 23 rice genotypes estimated from 14 quantitative traits based on mean values of genotypes over two locations (Assosa and Pawe) in 2017.

\begin{tabular}{|c|c|c|c|c|c|}
\hline Genotype & Minimum & Maximum & Mean & SD & CV $(\%)$ \\
\hline NM1-29-4-B-P-80-8 & 2.93 & 7.61 & 4.55 & 1.29 & 28.41 \\
\hline ART16-9-29-12-1-1-2-B-1-1 & 2.79 & 8.54 & 5.43 & 1.46 & 26.86 \\
\hline ART16-9-14-16-2-2-1-B-1-2 & 2.93 & 7.78 & 5.18 & 1.36 & 26.18 \\
\hline ART16-9-33-2-1-1-1-B-1-2 & 2.63 & 7.70 & 5.11 & 1.12 & 21.90 \\
\hline ART16-9-122-33-2-1-1-B-1-1 & 2.28 & 6.73 & 3.88 & 1.15 & 29.75 \\
\hline ART15-19-5-4-1-1-1-B-1-1 & 2.24 & 7.99 & 4.81 & 1.31 & 27.18 \\
\hline ART16-5-9-22-2-1-1-B-1-2 & 2.63 & 7.53 & 5.41 & 1.08 & 19.89 \\
\hline ART16-21-4-7-2-2-B-2-2 & 0.95 & 8.26 & 4.04 & 1.72 & 42.74 \\
\hline ART16-9-16-21-1-2-1-B-1-1 & 3.03 & 6.74 & 4.67 & 0.98 & 21.02 \\
\hline ART15-13-2-2-2-1-1-B-1-2 & 3.28 & 8.81 & 5.63 & 1.52 & 26.91 \\
\hline ART15-16-45-1-B-1-1-B-1-2 & 2.50 & 8.30 & 4.49 & 1.57 & 35.10 \\
\hline ART16-5-10-2-3-B-1-B-1-1 & 2.93 & 7.85 & 5.30 & 1.36 & 25.59 \\
\hline ART16-4-1-21-2-B-2-B-1-2 & 2.81 & 8.03 & 4.93 & 1.49 & 30.24 \\
\hline PARC.DAT.V-1.2013 & 3.16 & 9.71 & 6.77 & 1.57 & 23.16 \\
\hline PARC.DAT.V-2.2013 & 3.2 & 11.4 & 7.65 & 1.73 & 22.67 \\
\hline PARC.DAT.V-3.2013 & 3.32 & 9.32 & 6.55 & 1.52 & 23.21 \\
\hline ART15-16-31-2-1-1-1-B-1-1 & 0.95 & 7.91 & 3.98 & 1.63 & 40.82 \\
\hline ART16 5-10-22-4-B-1-B-B-1 & 3.07 & 9.69 & 5.37 & 1.72 & 32.03 \\
\hline ART16-4-13-1-2-1-1-B-1-1 & 2.24 & 8.45 & 4.50 & 1.54 & 34.10 \\
\hline ART16-9-5-28-3-13-1-B-2-1 & 3.08 & 7.49 & 5.50 & 1.13 & 20.56 \\
\hline ART16-9-9-25-2-1-1-B-2-1 & 3.6 & 11.4 & 6.14 & 2.03 & 33.08 \\
\hline ART16-9-19-11-2-2-2-B-1-2 & 2.99 & 8.39 & 4.65 & 1.47 & 31.64 \\
\hline NERICA-4(Check) & 2.57 & 9.10 & 4.64 & 1.61 & 34.65 \\
\hline Overall Mean & 0.95 & 11.39 & 5.18 & 1.70 & 32.81 \\
\hline
\end{tabular}

\subsection{Clustering of Genotypes}

The Euclidean distance matrix of 253 pair of genotypes estimated from quantitative traits was used to construct dendrogram based on the Unweighted Pair-group Methods with Arithmetic Means (UPGMA). The 23 rice genotypes were grouped into seven distinct clusters based on the genotypes mean values for 14 quantitative traits over two locations (Figure 3). Cluster III consisted of eight genotypes (34.78\%), other four clusters (Cluster I, IV, V and VII) each consisted of three (13.04\%) genotypes, while Cluster VI and II had two (ART16-9-33-2-1-1-1-B-1-2 and ART16-5-9-22-2-1-1-B1-2) and one (ART16-9-29-12-1-1-2-B-1-1) genotypes, respectively. The result suggested that the genotypes grouped under same cluster had similarity for many traits but dissimilarity to other genotypes in other clusters with one or more traits. Kulsum et al., (2011) and Hossain et al. (2015) indicated the homogeneous nature of the genotypes within the clusters.

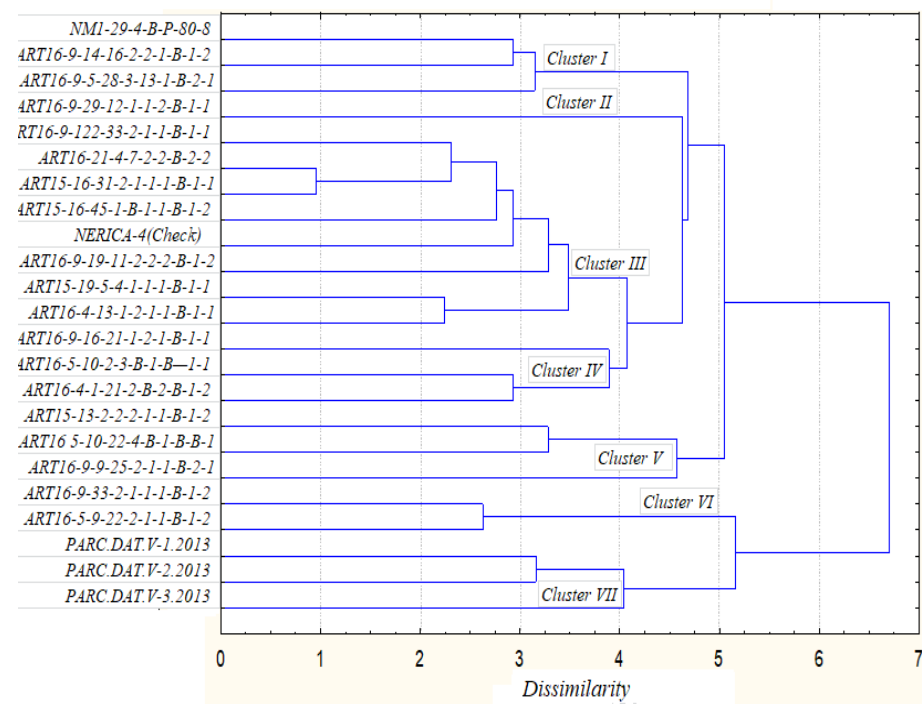

Figure3. Dendrogram generated based on UPGMA clustering method depicting genetic relationships among 23 rice genotypes for all traits. 


\subsection{Cluster Mean Analysis}

The distinguishing features of Cluster I and VII were by having higher mean values including for grain yield than the overall mean values of genotypes for all traits except the former cluster for VI, IV and the latter cluster for II, III and V. This suggested the higher chance of developing varieties through selection and further evaluation of genotypes from these two clusters. Cluster IV and VI had higher mean values than overall mean values of genotypes for days to heading, days to flowering, days to maturity, Protein content and grain yield, while Cluster V had higher mean values than overall mean values of genotypes for fertile tiller per plant, thousand grain weight, kernel width and kernel thickens.

According to the mean analysis of cluster, selection of genotypes from Cluster IV and VI is possible to obtain genotypes with highest grain yield and other desirable traits. It is suggested also to make cross among the two cluster members and genotypes from Cluster $\mathrm{V}$ to combine desirable traits in hybrids and searching better performing genotypes in subsequent segregating generations. Hossain $e t$ al. (2015), Sandhya et al. (2015) and Sowamiya and Venkatesan (2017) also suggested making cross among rice genotypes grouped under different clusters having varied desirable traits.

Table3. Cluster mean values for 14 quantitative traits of 23 rice genotypes evaluated at two locations (Pawe and Assosa) in 2017.

\begin{tabular}{|c|c|c|c|c|c|c|c|}
\hline Trait & I & II & III & IV & V & VI & VII \\
\hline Days to heading & 78.00 & 77.83 & 80.54 & 81.95 & 78.39 & 84.34 & 86.78 \\
\hline Days to flowering & 83.06 & 82.83 & 86.04 & 86.72 & 83.61 & 88.25 & 90.83 \\
\hline Days to maturity & 113.83 & 114.30 & 114.59 & 116.63 & 112.67 & 118.35 & 121.23 \\
\hline Plant height(cm) & 91.97 & 98.33 & 94.81 & 99.52 & 92.81 & 99.40 & 95.16 \\
\hline Panicle length(cm) & 20.96 & 20.93 & 21.11 & 23.02 & 20.08 & 20.29 & 22.18 \\
\hline Fertile tiller per plan & 7.37 & 7.35 & 6.55 & 7.68 & 7.72 & 7.05 & 8.20 \\
\hline Unfilled grains per panicle & 11.09 & 20.36 & 9.75 & 8.20 & 6.62 & 13.46 & 14.97 \\
\hline Thousand grainweight(g) & 25.80 & 26.47 & 27.29 & 26.95 & 27.96 & 27.37 & 27.69 \\
\hline Kernel length(mm) & 6.87 & 6.46 & 6.75 & 6.68 & 6.73 & 7.05 & 7.65 \\
\hline Kernel width(mm) & 2.30 & 2.42 & 2.42 & 2.45 & 2.46 & 2.36 & 2.27 \\
\hline Kernel thickens(mm) & 1.81 & 1.87 & 1.88 & 1.85 & 1.92 & 1.83 & 1.79 \\
\hline Length width ratio(mm) & 2.98 & 2.67 & 2.79 & 2.73 & 2.74 & 3.00 & 3.38 \\
\hline Protein content (\%) & 6.66 & 6.55 & 6.86 & 6.93 & 5.96 & 7.20 & 6.81 \\
\hline Grain yield(kg/h) & 5408 & 4509 & 5006 & 5529 & 4880 & 6281 & 5269 \\
\hline
\end{tabular}

\section{SUMMARY AND CONCLUSION}

The present study was conducted with the objective of assessing genetic diversity of upland rice genotypes for yield and yield related traits. Principal component analysis showed four principal components with eigen values ranged from 1.54 to 6.01. The estimated genetic distance of 23 pairs of accessions using. Euclidean distance ranged from 0.95 to 11.39 with mean of 5.18 and standard deviation of 1.7. The highest genetic distance was exhibited between PARC.DAT.V-2.2013 and ART16-9-9-25-2-1-1-B-2-1 while lowest genetic distance was between ART16-21-4-7-2-2-B-2-

2 and ART15-16-31-2-1-1-1-B-1-1 so, genotypes with high genetic distances between them have the potential to produce heterotic hybrids through crossing make among genotypes. Hence, the information generated from this study, rice breeder can be exploited for future rice breeding program. The study was also carried out for one season and at two locations. However, further evaluation of these breeding materials at more locations and year, different environments and agro-ecologies is advisable to confirm the promising results observed in the present study.

\section{ACKNOWLEDGMENT}

The author acknowledge to Dr. Mulugeta Atnafe, for his guidance and much helpful advice of my manuscript write-up. I am also thankful to the Ethiopian Institute of Agricultural Research (EIAR) for providing me the required financial support. My deepest gratefulness goes to Pawe Agricultural Research center for their support in field trial management and arrangement of the necessary facilities.

\section{REFERENCES}

[1] Brejda J.J., Moorman, T.B., Karlen, D.L. and Dao, T.H.2000.Identification of regional soil quality factors and indicators I. Central and Southern High- Plains. Soil Science Society of America Journal, 64(6): 2115-2124.

[2] Chakravorty, A., Ghosh P.D. and Sahu P.K.2013.Multivariate analysis of landraces of rice of West Bengal. American Journal of Experimental Agriculture. 3(1): 110-123. 
[3] Dogara, A.M. and Jumare, A.I., 2014. Origin, distribution and heading date in cultivated rice. International Journal of Plant Biology, 2(1): 1008.

[4] FAO , 2012 FAO Rice Market Monitor, Trade and Markets Division Food and Agriculture Organization of the United Nations Volume XV -Issue No. 3:

[5] Hossain S, Maksudu HMD and Jamilur RJ. 2015. Genetic Variability, Correlation and Path Coefficient Analysis of Morphological Traits in some Extinct Local Aman Rice (Oryza sativa L.). Journal of rice research.3:158.

[6] Kijima Y., Otsuka K, Futakuchi K 2008. The development of agricultural markets in sub Saharan Africa: the case of rice in Uganda. African Journal of Agriculture. Resour. Economics 8(4):253-264.

[7] Kulsum, M.U., Hasan, M.J., Begum, H., Billah, M.M. and Rahman, H. 2011. Genetic diversity of some restorer lines for hybrid rice development. Bangladesh Journal of Agricultural Research, 36(1): 21-28.

[8] MoARD. 2009. Ministry of Agriculture and Rural Development National Rice research and development strategy of Ethiopia. MOARD, Addis Ababa, Ethiopia.

[9] MoARD. 2010. Ministry of Agriculture and Rural Development National Rice research and development strategy of Ethiopia. MOARD, Addis Ababa, Ethiopia.

[10] Ojha,G.C., Sarawgi,A.K., Sharma, B. and Parikh,M. 2017. Principal component analysis of morphophysiological traits in rice germplasm accessions (Oryza sativa L.) under rainfed condition. International Journal of Chemical Studies, 5(5): 1875-1878

[11] Onyango, A.O. 2014. Exploring options for improving rice production to reduce hunger and poverty in Kenya. World Environment, 4(4): 172-179.

[12] Sandhya, M., Kumari, S. and Babu, G.S., 2015.Estimation of genetic divergence among elite genotypes of rice (Oryza sativa L.). The ecoscan, 9(1 and2): 407-409.

[13] Sohrabi, M., Rafii, M.Y., Hanafi, M.M., SitiNorAkmar, A. and Latif, M.A. 2012. Genetic diversity of upland rice germplasm in Malaysia based on quantitative traits. The Scientific World Journal.

[14] Sowamiya, C.A., and Venkatesan, M. 2017.Studies on Genetic Diversity in Rice (Oryza sativa L.), 6(9), 1749-1756.

[15] Tenorio FA, Ye C, Redona E, Sierra S, Laza M. Screening rice genetic resources for heat tolerance. SABRAO J. Breed. Gene. 2013; 45(3):371-381.

[16] Tuhina-Khatun, M., Hanafi, M.M., RafiiYusop, M., Wong, M.Y., Salleh, F.M. and Ferdous, J. 2015. Genetic variation, heritability, and diversity analysis of upland rice (Oryza sativa L.) genotypes based on quantitative traits. BioMed research international, 1-8

Citation: Atsedemariyam Tewachew, et.al, "Genetic Diversity Analysis of Upland Rice (Oryza Sativa L.) Genotypes in Benshangul Gumuz, Ethiopia" International Journal of Research Studies in Agricultural Sciences (IJRSAS), 2019; 5(10), pp. 22-28, http://dx.doi.org/10.20431/2454-6224.0510003

Copyright: (C) 2019 Authors. This is an open-access article distributed under the terms of the Creative Commons Attribution License, which permits unrestricted use, distribution, and reproduction in any medium, provided the original author and source are credited. 